\title{
Enhanced recovery after surgery for major orthopedic surgery: a narrative review
}

\author{
Yun Seong Choi ${ }^{2}$, Tae Woo Kim², Moon Jong Chang ${ }^{2}$, Seung-Baik Kang ${ }^{2,3}$ and Chong Bum Chang ${ }^{1,3^{*}}$ (1)
}

\begin{abstract}
Background: With increasing interest in enhanced recovery after surgery (ERAS), the literature on ERAS in orthopedic surgery is also rapidly accumulating. This review article aims to (1) summarize the components of the ERAS protocol applied to orthopedic surgery, (2) evaluate the outcomes of ERAS in orthopedic surgery, and (3) suggest practical strategies to implement the ERAS protocol successfully.

Main body: Overall, 17 components constituting the highly recommended ERAS protocol in orthopedic surgery were identified. In the preadmission period, preadmission counseling and the optimization of medical conditions were identified. In the preoperative period, avoidance of prolonged fasting, multimodal analgesia, and prevention of postoperative nausea and vomiting were identified. During the intraoperative period, anesthetic protocols, prevention of hypothermia, and fluid management, urinary catheterization, antimicrobial prophylaxis, blood conservation, local infiltration analgesia and local nerve block, and surgical factors were identified. In the postoperative period, early oral nutrition, thromboembolism prophylaxis, early mobilization, and discharge planning were identified. ERAS in orthopedic surgery reduced postoperative complications, hospital stay, and cost, and improved the patient outcomes and satisfaction with accelerated recovery. For successful implementation of the ERAS protocol, various strategies including the standardization of care system, multidisciplinary communication and collaboration, ERAS education, and continuous audit system are necessary.

Conclusion: The ERAS pathway enhanced patient recovery with a shortened length of stay, reduced postoperative complications, and improved patient outcomes and satisfaction. However, despite the significant progress in ERAS implementation in recent years, it has mainly focused on major surgeries such as arthroplasty. Therefore, further efforts to apply, audit, and optimize ERAS in various orthopedic surgeries are necessary.
\end{abstract}

Keywords: Enhanced recovery after surgery, Orthopedic surgery, Components, Outcomes, Implementation

\section{Background}

Enhanced recovery after surgery (ERAS) is a multimodal, multidisciplinary, and evidence-based protocol that promotes fast recovery by reducing the patient's surgical stress, organ dysfunction, and optimizing their

\footnotetext{
*Correspondence: ccbknee@gmail.com

${ }^{3}$ Department of Orthopedic Surgery, Seoul National University

Bundang Hospital, 82, Gumi-ro 173 Beon-gil, Bundang-gu, Seongnam-si, Gyeonggi-do 13620, South Korea

Full list of author information is available at the end of the article
}

physiologic function [1]. ERAS was first introduced in colorectal surgery by Kehlet, a Danish surgeon in 1997, and ERAS has spread to other surgical specialties, showing significant improvements in the clinical outcomes and costs [2].

With great interest in the ERAS pathway, literature on ERAS in orthopedic surgery is also rapidly increasing [36]. Recently, the ERAS Society reported the ERAS guidelines for hip-knee arthroplasty and spine surgery [4, 5], and even now, additional evidence supporting each ERAS

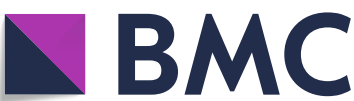

Part of Springer Nature
(0) The Author(s) 2022. Open Access This article is licensed under a Creative Commons Attribution 4.0 International License, which permits use, sharing, adaptation, distribution and reproduction in any medium or format, as long as you give appropriate credit to the original author(s) and the source, provide a link to the Creative Commons licence, and indicate if changes were made. The images or other third party material in this article are included in the article's Creative Commons licence, unless indicated otherwise in a credit line to the material. If material is not included in the article's Creative Commons licence and your intended use is not permitted by statutory regulation or exceeds the permitted use, you will need to obtain permission directly from the copyright holder. To view a copy of this licence, visit http://creativecommons.org/licenses/by/4.0/. The Creative Commons Public Domain Dedication waiver (http://creativeco mmons.org/publicdomain/zero/1.0/) applies to the data made available in this article, unless otherwise stated in a credit line to the data. 
component is being added. Numerous studies have also investigated the ERAS outcomes in orthopedic surgery from various aspects, including the length of stay, complications, clinical outcomes, and medical costs, and have reported promising results.

Nevertheless, the implementation of the ERAS protocol in orthopedic practice remains a difficult issue [7]. Recently, a number of studies on ERAS have reported various obstacles in ERAS implementation, such as reduced compliance and ERAS protocol deviation by providers and patients $[8,9]$. To transfer the ERAS protocol to be practiced successfully, practical strategies based on a sufficient understanding of ERAS components and their outcomes are necessary.

Therefore, this review article aims to (1) summarize the components of the ERAS protocol applied to orthopedic surgery, (2) evaluate the outcomes of ERAS in orthopedic surgery, and (3) suggest practical strategies to implement the ERAS protocol successfully.

\section{Components of ERAS protocol}

The ERAS components cover all perioperative periods, including preadmission, preoperative, intraoperative, and postoperative periods. In each period, multimodal treatments are given by different professional departments, such as surgery, anesthesia, and nursing (Table 1).

\section{Preadmission counseling}

Preoperative education is the process of explaining to a patient their treatment and recovery process during hospitalization. Although previous studies have reported that preoperative education does not reduce postoperative complications, improve pain, or shorten the hospital stay [10], good preoperative education can significantly reduce patient anxiety and emotional stress while increasing patient satisfaction and increasing patient trust [10, 11]. Kaye et al. reported on the importance of informing patients that postoperative pain might occur even if painkillers are used and to control the patients' unrealistic expectations for postoperative results[12].

\section{Optimization of medical condition}

Before surgery, it is necessary to check the patient's general health and optimize it to a condition suitable for surgery. A checklist to consider before surgery includes underlying disease (hypertension, diabetes mellitus, respiratory diseases, heart failure, chronic kidney disease, etc.), smoking and alcohol history, and nutritional status. The patient's underlying disease is identified through blood tests, imaging tests, and history-taking, and is usually optimized with the help of a specialist. It is also recommended to quit smoking. Pierre et al. reported that the group who quit smoking for more than 4 weeks had a $25 \%$ reduction in respiratory complications compared with the control group [13]. It is also recommended to abstain from alcohol. Eliasen et al. reported that alcohol consumption is associated with infection, lung complications, and long-term hospital stays [14]. It is also necessary to check the nutritional condition before surgery. Gu et al. reported that the albumin level is $<3.5 \mathrm{dg} / \mathrm{L}$ and there is a greater possibility of postoperative wound complications [15]. Preoperative anemia was associated with high postoperative transfusion rates and was significantly associated with postoperative infections, poorer physical function, and increased hospital stay and mortality [1619]. In particular, among patients undergoing total hip arthroplasty (THA) and total knee arthroplasty (TKA), preoperative anemia was very high, ranging from $24 \pm 9 \%$ to $44 \pm 9 \%$ [20], and more than $42 \%$ of hip fracture surgery patients present with anemia on admission [21, 22]. Preoperative anemia correction reduced the need for postoperative blood transfusion and could contribute to improving the patient's outcome [18, 23-25].

\section{Avoid prolonged fasting}

Previously, most patients had implemented nothing per oral after midnight (NPO) before surgery; however, since recently, clear fluid is allowed $2 \mathrm{~h}$ before the induction of anesthesia, and solid foods are allowed $6 \mathrm{~h}$ prior to the induction [26]. Prolonged fasting can cause catabolic conditions, which can increase the stress response to surgery and cause insulin resistance and hyperglycemia, prolonging the recovery period. In contrast, carbohydrate loading has been shown to decrease the insulin resistance and infection and increase the patient's well-being [27]. Carbohydrate loading involves taking the patients into surgery in a "metabolically fed state," which results in less protein and muscle loss after surgery [28]. However, two randomized controlled trials (RCTs) have compared the effects of carbohydrate loading versus preoperative fasting on glucose control in the spinal surgery population; neither could prove the advantage of carbohydrate loading $[29,30]$. Therefore, the routine use of carbohydrates before surgery is still not recommended.

\section{Multimodal analgesia}

The concept of multimodal analgesia is to combine various drugs and multiple routes of administration to achieve pain control, and it was reported to be effective for pain control in orthopedic surgery. Lee et al. stated that multimodal analgesia was very efficient in reducing postoperative pain in upper extremity surgery, such as for distal humerus fracture, elbow fracture and dislocation, multiple elbow ligament injuries, and osteoarthritis [31]. A combination of drugs with different mechanisms simultaneously targets different points in 
Table 1 Summary of the ERAS components for orthopedic surgery

\begin{tabular}{|c|c|c|}
\hline Period & Component & Contents \\
\hline \multirow[t]{2}{*}{ Preadmission } & Preadmission counseling & $\begin{array}{l}\text { Patients should be informed of the treatment they receive, what to expect, and their role in } \\
\text { the recovery process during their hospital stay }\end{array}$ \\
\hline & Optimization of medical condition & $\begin{array}{l}\text { Underlying disease: underlying disease should be identified through blood test, imaging } \\
\text { tests, and history taking, and optimized with the help of a specialist } \\
\text { Smoking: it is recommended to stop smoking at least } 4 \text { weeks before total joint arthroplasty } \\
\text { Alcohol: alcohol cessation is recommended before total joint arthroplasty } \\
\text { Malnutrition and anemia: preoperative correction of malnutrition and anemia is recom- } \\
\text { mended before total joint arthroplasty }\end{array}$ \\
\hline \multirow[t]{3}{*}{ Preoperative } & Avoid prolonged fasting & $\begin{array}{l}\text { Clear fluid was allowed } 2 \mathrm{~h} \text { before induction of anesthesia, and solid food was allowed } 6 \mathrm{~h} \\
\text { before, but routine intake of carbohydrates before surgery is still not recommended }\end{array}$ \\
\hline & Multimodal analgesia & $\begin{array}{l}\text { NSAID, paracetamol: decrease postoperative pain and reduce supplemental analgesic } \\
\text { (opioid) use following hip and knee replacement } \\
\text { Gabapentinoid: routine use is not recommended because of insufficient evidence } \\
\text { Antidepressant (duloxetine): significantly reduce opioid use and nausea } \\
\text { Opioid: current trend is to implement multimodal analgesia without opioid } \\
\text { Corticosteroid: can be used as a drug for preemptive analgesia with NSAID and pregabalin }\end{array}$ \\
\hline & PONV & $\begin{array}{l}\text { Corticosteroids (dexamethasone), serotonin (5HT3) antagonists (ondansetron), and dopa- } \\
\text { mine (D2) antagonists (droperidol) are commonly used to prevent PONV }\end{array}$ \\
\hline \multirow[t]{8}{*}{ Intraoperative } & Anesthetic protocol & $\begin{array}{l}\text { Anesthesia techniques (neuraxial versus general) more suitable for orthopedic surgery have } \\
\text { not yet been clarified. Routine use of spinal opioids or epidural anesthesia is unreasonable }\end{array}$ \\
\hline & Prevent hypothermia & $\begin{array}{l}\text { Normal body temperature should be maintained intraoperatively through prewarming and } \\
\text { humidification of anesthetic gases, warming IV and irrigation fluids, and warming blankets }\end{array}$ \\
\hline & Fluid management & $\begin{array}{l}\text { Fluid management should be adjusted to maintain the normal state of the body fluid } \\
\text { compartment, facilitate the excretion of waste, and return to oral intake as early as possible } \\
\text { after surgery }\end{array}$ \\
\hline & Urinary catheterization & $\begin{array}{l}\text { should be removed as soon as possible, ideally within } 24 \mathrm{~h} \text { after completion of surgery. } \\
\text { However, it should not be used routinely, and should be determined by patients' condition }\end{array}$ \\
\hline & Antimicrobial prophylaxis & $\begin{array}{l}\text { Antibiotics prophylaxis and dilute betadine lavage can prevent surgical site infection and } \\
\text { periprosthetic joint infection, but preoperative hair removal is not recommended }\end{array}$ \\
\hline & Blood conservation & $\begin{array}{l}\text { Tranexamic acid is effective in reducing blood loss and transfusion rate in orthopedic } \\
\text { surgery }\end{array}$ \\
\hline & LIA ad local nerve block & $\begin{array}{l}\text { LIA is effective for TKA and is more suitable for the ERAS protocol than a nerve block, which } \\
\text { can inhibit early mobilization by blocking the motor nerve }\end{array}$ \\
\hline & Surgical factors & $\begin{array}{l}\text { Surgical approach: there is no conclusive evidence that choice of surgical approach acceler- } \\
\text { ates the achievement of discharge criteria } \\
\text { Tourniquet, drainage: routine use is not recommended in orthopedic surgery } \\
\text { ICE therapy: effective in relieving pain, reducing swelling, and improving ROM }\end{array}$ \\
\hline \multirow{4}{*}{ Postoperative period } & Early oral nutrition & An early return to normal diet as soon as patients feel able is recommended \\
\hline & Thromboembolism prophylaxis & $\begin{array}{l}\text { Patients should be mobilized as soon as possible after surgery and should receive appropri- } \\
\text { ate antithrombotic prophylactic treatment }\end{array}$ \\
\hline & Early mobilization & $\begin{array}{l}\text { Patients should be mobilized as early as they are able because prolonged bed rest causes } \\
\text { thromboembolism, pulmonary complications, and muscle atrophy }\end{array}$ \\
\hline & Discharge planning & $\begin{array}{l}\text { Objective discharge criteria should be established so that patients can be discharged } \\
\text { directly } \\
\text { to their home }\end{array}$ \\
\hline
\end{tabular}

NSAID nonsteroidal anti-inflammatory drugs; PONV prevention of postoperative nausea and vomiting; $I V$ intravenous; LIA local infiltration analgesia; TKA total knee arthroplasty; ERAS enhanced recovery after surgery; ROM range of motion

the pain pathway [32]. Nonsteroidal anti-inflammatory drugs (NSAID)s have a great advantage in reducing the pain after arthroplasty [33]. However, they has side effects, including gastrointestinal (GI) tract ulcers, renal dysfunction, and cardiovascular disease (CVD). Paracetamol is effective in reducing mild to moderate pain, and side effects, such as nausea and vomiting (N/V), skin irritation, and thrombocytopenia, are less common [34].
Gabapentinoids inhibit the release of neurotransmitters, such as substance $P$, resulting in decreased nerve excitability and pain. However, due to insufficient evidence to demonstrate the effectiveness of gabapentinoids, the routine use of gabapentinoids in the ERAS protocol is not recommended $[5,35]$. Opioids have numerous side effects, including drowsiness, respiratory depression, $\mathrm{N} / \mathrm{V}$, and urinary retention; therefore, the current trend 
is to implement multimodal analgesia without opioids [5]. In addition, antidepressants (duloxetine) are effective in reducing opioid use and nausea [36]. Corticosteroids are potent anti-inflammatory agents that have been widely used in various perioperative settings to reduce the postoperative pain. In particular, previous studies have reported that corticosteroids can be used as a drug for preemptive analgesia with NSAIDs and pregabalin to control post-TKA pain and effectively control postoperative pain without wound complications $[37,38]$.

\section{Prevention of postoperative nausea and vomiting (PONV)}

PONV is one of the most distressing symptoms in patients, along with postoperative pain. The well-known risk factors for PONV include the following: (1) female sex, (2) non-smoking status, (3) prior history of motion sickness, and (4) use of postoperative opioids [39]. The treatment for PONV is mainly managed by pharmacological treatment. Popular drugs include corticosteroids (dexamethasone), serotonin-5-HT3 antagonists (ondansetron), and dopamine (D2) antagonists (droperidol), which have been shown to reduce PONV more effectively [40]. Koh et al. reported that PONV could be significantly reduced when dexamethasone was used together with 5HT3 antagonists before TKA compared with when 5HT3 antagonists were used alone [37].

\section{Anesthetic protocol}

In orthopedic lower limb surgery, neuraxial anesthesia is generally used more frequently than general anesthesia [41]. This is because neuraxial anesthesia reduces pulmonary complications, PONV, postoperative pain, and ileus, thus reducing the hospital stay [42]. However, previous studies have reported no significant difference in the mortality, surgical duration, surgical site infections (SSI), nerve palsy, thromboembolic disease, and blood loss between neuraxial anesthesia and general anesthesia [43]; moreover, urinary bladder dysfunction is more reduced under general anesthesia [5]. Additional studies on the two anesthesia techniques are needed. In spinal anesthesia, opioids seem to reduce the pain after surgery [44]; however, they are not easy to use because side effects, such as delay of recovery, urinary retention, response, and PONV, have been identified [45]. In epidural analgesia, which is performed for postoperative pain control, the advantage of reducing pain seems obvious; however, it has side effects, including delayed recovery, hypotension, and urinary retention [46]. Therefore, the routine use in THA and TKA seems unreasonable.

In spine surgery, there was no difference between nongeneral and general anesthesia in terms of readmission rates, complications, and length of stay (LOS) [47]. However, many options exist for general anesthesia due to the wide range of available drugs and delivery methods. Brown and Gille et al. reported that the use of neuromuscular blockade reduced airway pressure and muscle damage associated with prolonged retraction during spine surgery $[48,49]$.

\section{Prevent hypothermia}

Hypothermia is common in patients who have undergone orthopedic surgery [50]. Previous studies have reported the incidence of hypothermia for THA, TKA, and hip fracture to be $26.3 \%, 28.0 \%$, and $10 \%$, respectively $[51,52]$. In addition, Williams et al. reported that inadvertent hypothermia was significantly associated with a higher 30-day readmission rate and a 30-day mortality in elderly patients with hip fracture [52]. If the patient fails to maintain normothermia during surgery and heat loss occurs, stress responses, such as nitrogen loss and the release of cortisol and catecholamine, increase [1]. This may increase the infection, coagulopathy, blood transfusion rate, cardiovascular complications, and opioid need, which may adversely affect the postoperative outcome [53]. Lower preoperative temperature, female sex, lower body mass index, older age, adult reconstruction by specialty, and hip and pelvic procedures by anatomic region are known risk factors for hypothermia during orthopedic surgery [50]. Methods of maintaining normothermia include prewarming and humidification of anesthesia gas, preheating of intravenous (IV) and irrigation fluids, and forced-air warming of blankets and devices [5]. Rosenkilde et al. reported that unintended perioperative hypothermia in total joint arthroplasty was identified in $13 \%$ of the patients in the prewarming group and $43 \%$ of the patients in the control group [54].

\section{Fluid management}

There are three fluid therapies: (1) liberal fluid therapy, (2) restricted fluid therapy, and (3) goal-directed fluid therapy (GDT) [55]. Liberal fluid therapy involves injecting a large amount of fluid to improve the tissue oxygen delivery and maintain the urine output because the patients undergoing surgery are in a hypovolemic state with long fasting times and high blood loss [56]. However, this therapy can cause hypervolemia, which can lead to tissue edema, pulmonary edema, and cardiac complications [57]. Therefore, new management methods, such as restricted fluid therapy, have been introduced to prevent such occurrences. In restrictive fluid therapy, fluid is injected to achieve zero balance [58]. Although this may avoid hypervolemia, it can cause hypotension and decrease perfusion to the vital organs, causing organ dysfunction, such as acute kidney injury [57]. GDT monitors the hematologic parameters (pulse pressure variation, delta stroke volume, central venous pressure, and urine 
output) before and after surgery to achieve normal use of fluid or inotropes [59]. GDT is highly recommended in the ERAS protocol. However, unlike colorectal surgery, where GDT is important, it does not seem to be as important for surgeries, such as THA and TKA. This is because the loss of blood and fluid is lower than expected in arthroplasty; additionally, oral intake is more likely to occur sooner after arthroplasty. Fluid management should be adjusted to maintain the normal state of the body fluid compartment, facilitate the excretion of waste, and return to oral intake as early as possible [5].

\section{Urinary catheterization}

Postoperative urinary retention (POUR) can lead to urinary tract infection (UTI), wound infection, and periprosthetic infection [60]. Previous studies have demonstrated that indwelling urinary catheterization prevents POUR and significantly reduces the incidence of UTI [61]. Therefore, several orthopedic surgeons perform urinary catheterization in these patients. However, recent studies have reported that POUR does not increase without indwelling urinary catheterization owing to the development of surgical and anesthesia techniques [62], and the recent trend toward rapid recovery and early mobilization of patients has led to the direction of not performing indwelling urinary catheterization [63]. However, when the operation time is long and it is necessary to check the urinary output, indwelling urinary catheterization should be used as a guide for fluid resuscitation. When indwelling urinary catheterization is used, it should be removed as soon as possible, ideally within $24 \mathrm{~h}$ after the completion of surgery [5]. Indwelling urinary catheterization should not be used routinely, and it should be determined based on the patient's condition.

\section{Antimicrobial prophylaxis}

Antibiotic prophylaxis is a very important management strategy to prevent SSI and periprosthetic joint infection (PJI) in patients undergoing arthroplasty [64]. Several orthopedic surgeons refer to the Surgical Care Improvement Project (SCIP) guidelines for antibiotic prophylaxis.

According to the SCIP guideline [65],

(1) In principle, prophylactic antibiotics should be injected within $1 \mathrm{~h}$ prior to surgical incision, but if the patient needs to be injected with vancomycin or fluoroquinolone, it should be injected within $2 \mathrm{~h}$ before surgical incision.

(2) Patients should be prescribed a suitable antibiotic depending on the type of surgery.

(3) Preventive antibiotics should be stopped within $24 \mathrm{~h}$ of the completion of the surgery.
Previous studies have reported that patients who received antibiotics more than $2 \mathrm{~h}$ before incision had an approximately two- to sixfold increased risk of SSI [66]. In addition, if methicillin-resistant Staphylococcus aureus and coagulase-negative staphylococci are identified, vancomycin should be administered, and if the patient is allergic to penicillin and cephalosporin, fluoroquinolone should be administered. Patients undergoing orthopedic surgery are most likely to be infected with $S$. aureus and streptococcal species. Therefore, first-generation cephalosporins (typically cefazolin) are commonly administered [67]. Moreover, it is recommended that prophylactic antibiotics should be terminated within $24 \mathrm{~h}$ even if there is drainage after surgery [68]. In addition, it was reported that dilute betadine lavage before surgical wound closure in total joint arthroplasty is an effective measure to reduce the risk of acute postoperative PJI [69], and that skin preparation using either alcohol-based iodine or chlorhexidine solution could provide a more favorable longer-lasting effect for skin antisepsis in spine surgery [4]. Meanwhile, there was consensus that hair removal before surgery has no significant effect on reducing the incidence of SSI; however, shaving increases the incidence of SSI [70].

\section{Blood conservation}

Significant blood loss can occur in tumor surgery, pelvic surgery, and primary and revision arthroplasty. Blood loss has been treated by blood transfusion; however, this is not an easy option because it can cause serious complications, such as infection and disease transmission [71]. A decrease in the blood loss and transfusion rate may be achieved using combined local and systemic tranexamic acid [5]. Tranexamic acid is an antifibrinolytic drug that competitively suppresses the plasmin activation of plasminogen, thereby preventing the destruction of fibrin clotting and reducing blood loss. Gautam et al. revealed that tranexamic acid was effective in reducing blood loss and blood transfusion in patients undergoing TKA [72], and Haj-Younes et al. also reported that intravenous tranexamic acid reduced the proportion of patients requiring blood transfusions when undergoing hip fracture surgery [73]. In addition, tranexamic acid can be administered via topical routes in addition to the intravenous and oral routes. Indeed, Wong et al. added tranexamic acid to normal saline at the end of surgery and applied it topically to the joint surface, demonstrating its effectiveness in reducing the blood loss [74]. However, it is important to be aware that it can increase the risk of deep vein thrombosis (DVT) [75]. 
Local infiltration analgesia (LIA) and local nerve block

LIA is the administration of painkillers around the surgical site during surgery, mostly in TKA. LIA is mainly composed of a combination of multimodal analgesics, including local anesthetics, NSAIDs, opioids, and steroids, and is effective for pain that can occur 6-12 h after surgery [76]. In fact, it is a technique used by many orthopedic surgeons for patients undergoing TKA. In addition to TKA, it was reported that LIA was also effective in ankle and shoulder surgery. Li et al. stated that LIA with ropivacaine could provide better early postoperative pain management, with a reduction in VAS scores for ankle fracture surgery [77]. Moreover, Sicard et al. reported that LIA was not less effective than interscalene nerve block for early postoperative pain control after total shoulder arthroplasty [78]. However, in THA, it was reported that LIA did not significantly reduce the postoperative pain [79]. Nerve block is a technique used for analgesic purposes, especially femoral nerve block, which has been proven to significantly reduce postoperative pain compared with other epidural analgesia or patient-controlled analgesia (PCA) [80]. However, the sciatic nerve block did not offer any particular advantage compared with other analgesic techniques for hip or knee replacement [80]. Since nerve block can block the motor nerve, LIA is generally considered to be a safer technique. The motor block can be harmful to muscle function and makes early mobilization difficult [81]; therefore, the routine use of nerve block techniques is not recommended in the ERAS protocol.

\section{Surgical factors}

There is insufficient evidence that one particular surgical approach may shorten the length of the patient's hospitalization period compared with other surgical approaches in arthroplasty and spinal surgery $[4,82]$. The use of tourniquets when performing TKA can generally improve vision by reducing bleeding during surgery [83]. However, the routine use of tourniquets in the ERAS protocol is not recommended, as DVT, peripheral nerve damage, and skin irritation have also been reported. Additionally, hematoma, which may occur after arthroplasty, acts as a good medium for bacteria causing SSI or PJI; therefore, several orthopedic surgeons usually connect the drain to the surgical site and complete the surgery. However, there have been reports that blood loss and transfusion rate can be increased and retro-infection can occur through a drain in THA [84], and four RCTs showed that drains did not reduce the incidence of either SSI or postoperative hematoma during spinal surgery [85-88]. Therefore, the routine use of drains is not recommended in the recent ERAS protocol. Meanwhile, nonpharmaceutical treatments, such as cryotherapy, play a role in addressing immediate postoperative complications, such as pain and swelling. Zhong et al. reported that applying an ice pack after TKA is effective in relieving pain, reducing swelling, and improving the range of motion (ROM) [89].

\section{Early oral nutrition}

No studies have investigated the direct relationship between postoperative nutritional supplementation and accelerating the achievement of discharge criteria. However, encouraging patients to eat and drink as soon as possible is considered an essential component of the ERAS protocol, as returning to normal food intake can help patients return to normal behavior [5].

\section{Thromboembolism prophylaxis}

Venous thromboembolism (VTE) has been reported to occur in approximately $40-60 \%$ of major orthopedic surgeries (THA, TKA, and hip fracture) without the use of preventive anticoagulants $[90,91]$. The drugs commonly used for VTE prophylaxis include low-molecular-weight heparin, warfarin, rivaroxaban, fondaparinux, and aspirin [92]. Mechanical therapy commonly used for VTE prophylaxis includes graduated compression stockings and intermittent pneumatic compression devices (IPCDs) [92]. The main VTE prophylaxis guidelines are the American College of Chest Physicians (ACCP) guidelines and the American Academy of Orthopedic Surgeons (AAOS) guidelines. The recently announced 10th Amendment ACCP guidelines consider major orthopedic surgeries such as THA, TKA, and hip fracture a high-risk group for VTE and recommend that one of the drugs described above be used for at least 10-14 days and, if possible, up to 35 days after surgery [91]. However, although VTE prophylaxis reduces the frequency of thrombosis, it seems that the proportion of asymptomatic thrombosis is large, and the evidence that such thrombosis progresses to symptomatic thrombosis or pulmonary embolism is weak [93]. Therefore, AAOS considers the side effects of antithrombotic agents, such as bleeding, and suggests a guideline to prevent them, with additional emphasis on symptomatic DVT and pulmonary embolism (PE) $[1,53]$. The guidelines that recommended a period of 10-35 days for VTE prophylaxis after THA, TKA, and hip fracture did not consider "early mobility." Therefore, the AAOS guidelines considered "early mobility." In fact, early mobility can reduce the occurrence of DVT, thereby reducing the period of prophylaxis and hospitalization [94].

\section{Early mobilization}

The patient should be mobilized as soon as possible after surgery. If the patient prolongs bed rest, the patient will have thromboembolism, pulmonary complications, and 
muscle atrophy [95] and eventually the hospitalization period will be extended. In fact, Guerra et al. reported that early mobility reduced hospitalization by an average of 1.8 days in total joint arthroplasty [96], and Deng et al. reported that patient-reported outcome measures (PROMs) score of the early mobilization group was significantly better than that of the late mobilization group after distal radius fracture surgery [97].

\section{Discharge planning}

The ERAS of THA and TKA may include the objective discharge criteria for patients to be discharged directly to their home. It is necessary to clearly define the degree of independent dressing, the ability to get in and out of bed, the ability to sit and get up in a chair/toilet, the ability to be independent of personal care, and the ability to walk using a walker or crutches [98].

\section{Outcomes of ERAS in orthopedic surgery (Table 2)}

\section{LOS}

ERAS reduced LOS [3, 11, 99-111]. In particular, Morrell et al. reported that 2428 patients in the ERAS group had a significant decrease in the LOS after THA and TKA compared with 5361 patients in the control group [3]. Furthermore, Sun et al. stated that, after anterior cruciate

Table 2 Summary of the outcomes of ERAS in orthopedic surgery

\begin{tabular}{|c|c|c|c|c|c|}
\hline Study & Year & Surgery type & Study type & Study/control (N) & Result \\
\hline Auyong et al. [100] & 2015 & TKA & Retrospective & $126 / 126$ & $\begin{array}{l}\text { Reduced LOS, transfusion rate, postop- } \\
\text { erative nausea }\end{array}$ \\
\hline Zhu et al. [11] & 2017 & THA, TKA & Meta-analysis & $4205 / 5731$ & Reduced LOS, complication \\
\hline Gwynne et al. [99] & 2017 & TKA & Prospective & $528 / 507$ & $\begin{array}{l}\text { Reduced LOS, Oxford knee score was } \\
\text { improved }\end{array}$ \\
\hline Deng et al. [101] & 2018 & THA, TKA & Meta-analysis & $6944 / 9755$ & $\begin{array}{l}\text { Reduced LOS, mortality, transfusion, } \\
\text { complications }\end{array}$ \\
\hline Hu et al. [112] & 2019 & Joint, fx, spine surgery & Meta-analysis & $9700 / 11,143$ & $\begin{array}{l}\text { Reduced incidence of postoperative } \\
\text { complications, 30-day mortality rate }\end{array}$ \\
\hline Garriga et al. [102] & 2019 & TKA & Retrospective & 486,579 & $\begin{array}{l}\text { Reduced LOS, bed-day costs, complica- } \\
\text { tions } \\
\text { Oxford knee score was improved }\end{array}$ \\
\hline Kang et al. [109] & 2019 & Intertrochanteric fx & Prospective & $50 / 50$ & $\begin{array}{l}\text { Reduced LOS, complications, readmis- } \\
\text { sion rate, opioid consumption } \\
\text { Harris hip score was improved }\end{array}$ \\
\hline Jiang et al. [103] & 2019 & TKA & Prospective & $106 / 141$ & $\begin{array}{l}\text { Reduced postoperative pain, LOS, } \\
\text { blood loss } \\
\text { Knee society score and ROM degree } \\
\text { were improved }\end{array}$ \\
\hline Xiao et al. [113] & 2019 & Close reduction of distal radius $\mathrm{fx}$ & Prospective & $72 / 114$ & $\begin{array}{l}\text { Reduced complications, improved } \\
\text { patient-rated wrist evaluation score }\end{array}$ \\
\hline Yin et al. [104] & 2020 & Intertrochanteric fx & $\mathrm{RCT}$ & $30 / 30$ & Reduced LOS \\
\hline Wang et al. [105] & 2020 & Spine surgery & Retrospective & $96 / 96$ & Reduced LOS \\
\hline Ripollés-Melchor et al. [106] & 2020 & THA, TKA & Prospective & $163 / 517$ & $\begin{array}{l}\text { Reduced LOS, complications within } \\
30 \text { days after surgery }\end{array}$ \\
\hline Pritchard et a1 [115] & 2020 & THA, TKA & Systematic review & - & Improved cost-effectiveness \\
\hline Tong et al. [110] & 2020 & Spine surgery & Systematic review & - & $\begin{array}{l}\text { Reduced LOS, opioid consumption, } \\
\text { improved cost-effectiveness }\end{array}$ \\
\hline Frassanito et al. [107] & 2020 & THA, TKA & Prospective & 207 & $\begin{array}{l}\text { Reduced LOS, opioid consumption, } \\
\text { improved satisfaction score }\end{array}$ \\
\hline Sun et al. [111] & 2020 & ACL reconstruction & Prospective & $30 / 30$ & $\begin{array}{l}\text { Reduced LOS } \\
\text { Improved satisfaction score, Lysholm } \\
\text { knee scoring scale }\end{array}$ \\
\hline Leiss et al. [114] & 2021 & THA & Retrospective & 109 & $\begin{array}{l}\text { Harris hip score, WOMAC score, and } \\
\text { EQ-5D were improved } \\
\text { Improved satisfaction score }\end{array}$ \\
\hline Liu et al. [108] & 2021 & $\operatorname{Hip} f_{x}$ & Meta-analysis & 9869 & Reduced LOS, TTS, and complications \\
\hline Morrell et al. [3] & 2021 & THA, TKA & Systematic review & $2428 / 5361$ & Reduced LOS \\
\hline
\end{tabular}


ligament reconstruction, 30 patients in the ERAS group had a significant decrease in LOS compared with 30 others in the control group (7.3 days versus 11.5 days, respectively) [111]. Wang et al. reported that the ERAS group had a shorter median LOS than the non-ERAS group in short-level lumbar fusion $(12.30 \pm 3.03$ of ERAS group; $15.50 \pm 1.88$ in non-ERAS group) [105].

\section{Complication}

There were fewer incidences of complications in the ERAS group than in the non-ERAS group [11, 101, 102, $106,108,109,112,113]$. Zhu et al. reported that 3262 patients in the ERAS group had a significant decrease in complications after THA and TKA compared with 4527 patients in the control group [11]. Xiao et al. reported that 72 patients in the ERAS group had a significant decrease in close reduction of distal radius fracture compared with 114 patients in the control group [113]. In addition, Liu et al. also described that 1852 patients in the ERAS group had a significant decrease in complications after hip fracture surgery compared with 1302 patients in the control group [108].

\section{PROM}

Patients in the ERAS group had better postoperative PROM scores than those in the non-ERAS group [99, 102, 103, 107, 109, 111, 113, 114]. In particular, Kang et al. reported that patients in the ERAS group had better 3-month Harris hip scores after intertrochanteric fracture surgery than those in the non-ERAS group [109], and Frassanito et al. reported that satisfaction scores of patients who underwent total joint arthroplasty with the ERAS protocol improved [107]. Leiss et al. conducted a retrospective study of 109 patients who underwent cementless THA with the ERAS protocol; their Harris hip score, Western Ontario and McMaster Osteoarthritis Index (WOMAC) score, EuroQol-5 Dimensions (EQ-5D), and patient satisfaction showed continuous improvement over a follow-up of 12 months after surgery [114].

\section{Cost}

The ERAS protocol has shown significant cost-effectiveness while reducing the LOS and complications [102, 110, 115]. Garriga et al. evaluated 486,579 patients who underwent TKA and reported that LOS and bed-day costs decreased from 5.8 to 3.7 days and from $£ 7607$ to £5276, from April 2008 to December 2016 [102]. Tong et al. reviewed 22 studies evaluating the cost-effectiveness of adult spine surgery with the ERAS protocol and reported that ERAS may improve cost-effectiveness to varying degrees for spinal procedures [110].

\section{Implementation of ERAS: from protocol to practice}

Although well-established ERAS protocols have shown promising outcomes, their implementation in practice remains a difficult issue. An increasing number of studies on ERAS have reported various obstacles to ERAS implementation, such as reduced compliance and ERAS protocol deviation by providers and patients [116-120]. Several practical strategies are required for the successful implementation of the ERAS protocol.

\section{Multimodal and standardized care system}

Each ERAS element is closely related and has a synergistic effect with the others [6]. For example, early mobilization can be achieved by pain control, reduced bleeding, improved PONV, and restricted fluid therapy. Therefore, to implement the ERAS protocol effectively, a multimodal approach to utilize all available ERAS elements is essential, and the standardization of patient care systems, such as set order or clinical pathway, is necessary $[6,117]$. Foni et al. described that the implementation of $\mathrm{CP}$ in TKA was related to a reduction in the length of hospital stay from 6.3 to 4.9 days, and a reduction in cost compared with the control group [121]. Schwarzkopf et al. also reported that the postoperative PROM score was significantly better than the preoperative PROM score when CP was implemented [122].

\section{Multidisciplinary communication and collaboration}

ERAS elements are carried out by various professional departments, such as surgery, anesthesia, nursing, and physical therapy. The sharing of patients' information and communication between ERAS participants are key to successful multidisciplinary collaboration [119]. Formal structures to encourage communication, such as consistent ERAS team meetings, can be helpful for multidisciplinary collaboration [116].

\section{ERAS education}

Traditional typical care, general resistance to change, and individual surgeon preference are known to be obstacles to ERAS adherence $[116,117]$. To reduce the providerderived pathway deviation unaccompanied by clinical rationale, ERAS education for all providers is necessary [118]. The empowerment of patients by ERAS education can also promote them to work toward recovery [119].

\section{Continuous audit system}

To improve ERAS compliance, continuous feedback with an audit system is necessary. Ament et al.[123] reported that the loss of audit feedback can be a reason for the diminished effectiveness of the ERAS pathway. 
Multidisciplinary communication and collaboration can work based on the audit system, and the audit system can also update the ERAS protocol in light of new evidence [6].

\section{Future of ERAS}

Evidence-based ERAS protocols in orthopedic surgery have been well established with numerous supporting studies, especially in hip and knee arthroplasty and spinal surgery. ERAS in orthopedic surgery successfully enhanced patient recovery with shortened LOS, reduced postoperative complications, and improved clinical outcomes and satisfaction. However, ERAS studies on other types of surgery, including fracture, arthroscopy, and trauma, are very limited, and which elements are more important among numerous ERAS items still remains unclear. For the successful implementation of ERAS in various fields of orthopedic surgery, future studies need to focus on the optimization of the ERAS protocol depending on each surgery type through continuous audit and feedback.

\section{Conclusion}

The ERAS pathway enhanced patient recovery with a shortened LOS, reduced postoperative complications, and improved patient outcomes and satisfaction. However, despite the significant progress in ERAS implementation in recent years, it has mainly focused on major surgeries such as arthroplasty. Therefore, further efforts to apply, audit, and optimize ERAS in various orthopedic surgeries are necessary.

\begin{abstract}
Abbreviations
ERAS: Enhanced recovery after surgery; THA: Total hip arthroplasty; TKA: Total knee arthroplasty; NPO: Nothing per oral after midnight; NSAID: Nonsteroidal anti-inflammatory drugs; Gl: Gastrointestinal; CVD: Cardiovascular disease; N/V: Nausea and vomiting; PONV: Postoperative nausea and vomiting; SSI: Surgical site infections; IV: Intravenous; GDT: Goal-directed fluid therapy; POUR: Postoperative urinary retention; UTI: Urinary tract infection; PJI: Periprosthetic joint infection; SCIP: Surgical Care Improvement Project; DVT: Deep vein thrombosis; LIA: Local infiltration analgesia; PCA: Patient-controlled analgesia; ROM: Range of motion; VTE: Venous thromboembolism; IPCD: Intermittent pneumatic compression devices; ACCP: American College of Chest Physicians; AAOS: American Academy of Orthopedic Surgeons; LOS: Length of stay; PROM: Patient-reported outcome measures; WOMAC: Western Ontario and McMaster Osteoarthritis Index; EQ-5D: EuroQol-5 Dimensions.
\end{abstract}

\section{Acknowledgements}

Not applicable.

\section{Authors' contributions}

All authors were involved equally in all aspects of the creation of this manuscript. All authors read and approved the final manuscript.

\section{Funding}

The authors received no financial support for the research, authorship, and/or publication of this article.
Availability of data and materials

Not applicable.

\section{Declarations}

Ethics approval and consent to participate

Not applicable.

\section{Consent for publication}

Not applicable.

\section{Competing interests}

The authors declare that they have no competing interests.

\section{Author details}

${ }^{1}$ Department of Orthopedic Surgery, Seoul National University College of Medicine, Seoul, South Korea. ${ }^{2}$ Department of Orthopedic Surgery, SMGSNU Boramae Medical Center, Seoul, South Korea. ${ }^{3}$ Department of Orthopedic Surgery, Seoul National University Bundang Hospital, 82, Gumi-ro 173 Beon-gil, Bundang-gu, Seongnam-si, Gyeonggi-do 13620, South Korea.

Received: 5 November 2021 Accepted: 8 February 2022

Published online: 22 February 2022

\section{References}

1. Soffin EM, YaDeau JT (2016) Enhanced recovery after surgery for primary hip and knee arthroplasty: a review of the evidence. Br J Anaesth 117(suppl 3):iii62-iii72

2. Bertolaccini L, Brunelli A (2019) Devising the guidelines: the techniques of uniportal video-assisted thoracic surgery-postoperative management and enhanced recovery after surgery. J Thorac Dis 11 (Suppl 16):S2069-S2072

3. Morrell AT, Layon DR, Scott MJ, Kates SL, Golladay GJ, Patel NK (2021) Enhanced recovery after primary total hip and knee arthroplasty: a systematic review. J Bone Joint Surg Am 10:2106

4. Debono B, Wainwright TW, Wang MY, Sigmundsson FG, Yang MMH, Smid-Nanninga $\mathrm{H}$ et al (2021) Consensus statement for perioperative care in lumbar spinal fusion: Enhanced Recovery After Surgery (ERAS ${ }^{\circledR}$ ) Society recommendations. Spine J 21 (5):729-752

5. Wainwright TW, Gill M, McDonald DA, Middleton RG, Reed M, Sahota O et al (2020) Consensus statement for perioperative care in total hip replacement and total knee replacement surgery: Enhanced Recovery After Surgery $\left(\operatorname{ERAS}\left({ }^{\circledR}\right)\right)$ Society recommendations. Acta Orthop 91(1):3-19

6. Ljungqvist $O$, Scott M, Fearon KC (2017) Enhanced recovery after surgery: a review. JAMA Surg 152(3):292-298

7. Ljungqvist $\mathrm{O}$, de Boer HD, Balfour A, Fawcett WJ, Lobo DN, Nelson $\mathrm{G}$ et al (2021) Opportunities and challenges for the next phase of enhanced recovery after surgery: a review. JAMA Surg 156(8):775-784

8. Li ZE, Lu SB, Kong C, Sun WZ, Wang P, Zhang ST (2020) Impact of compliance with an enhanced recovery after surgery program on the outcomes among elderly patients undergoing lumbar fusion surgery. Clin Interv Aging 15:2423-2430

9. Berkelmans GHK, Kingma BF, Fransen LFC, Nieuwenhuijzen GAP, Ruurda JP, van Hillegersberg $R$ et al (2020) Feeding protocol deviation after esophagectomy: a retrospective multicenter study. Clin Nutr 39(4):1258-1263

10. Halaszynski TM, Juda R, Silverman DG (2004) Optimizing postoperative outcomes with efficient preoperative assessment and management. Crit Care Med 32(4 Suppl):S76-86

11. Zhu S, Qian W, Jiang C, Ye C, Chen X (2017) Enhanced recovery after surgery for hip and knee arthroplasty: a systematic review and metaanalysis. Postgrad Med J 93(1106):736-742

12. Kaye AD, Urman RD, Cornett EM, Hart BM, Chami A, Gayle JA et al (2019) Enhanced recovery pathways in orthopedic surgery. J Anaesthesiol Clin Pharmacol 35(Suppl 1):S35-S39 
13. Pierre S, Rivera C, Le Maître B, Ruppert AM, Bouaziz H, Wirth $N$ et al (2017) Guidelines on smoking management during the perioperative period. Anaesth Crit Care Pain Med 36(3):195-200

14. Eliasen M, Grønkjær M, Skov-Ettrup LS, Mikkelsen SS, Becker U, Tolstrup JS et al (2013) Preoperative alcohol consumption and postoperative complications: a systematic review and meta-analysis. Ann Surg 258(6):930-942

15. Gu A, Malahias MA, Strigelli V, Nocon AA, Sculco TP, Sculco PK (2019) Preoperative malnutrition negatively correlates with postoperative wound complications and infection after total joint arthroplasty: a systematic review and meta-analysis. J Arthroplasty 34(5):1013-1024

16. Jans $\varnothing$, Jørgensen $C$, Kehlet $H$, Johansson PI (2014) Role of preoperative anemia for risk of transfusion and postoperative morbidity in fast-track hip and knee arthroplasty. Transfusion 54(3):717-726

17. Baron DM, Hochrieser H, Posch M, Metnitz B, Rhodes A, Moreno RP et al (2014) Preoperative anaemia is associated with poor clinical outcome in non-cardiac surgery patients. Br J Anaesth 113(3):416-423

18. Zhao M, Geng X, Wang C, Zeng L, Tian H (2019) The value of tranexamic acid for patients with preoperative anemia in primary total knee arthroplasty. Eur J Med Res 24(1):28

19. Grosso MJ, Boddapati V, Cooper HJ, Geller JA, Shah RP, Neuwirth AL (2020) The effect of preoperative anemia on complications after total hip arthroplasty. J Arthroplasty 35(6s):S214-S218

20. Spahn DR (2010) Anemia and patient blood management in hip and knee surgery: a systematic review of the literature. Anesthesiology 113(2):482-495

21. Gruson KI, Aharonoff GB, Egol KA, Zuckerman JD, Koval KJ (2002) The relationship between admission hemoglobin level and outcome after hip fracture. J Orthop Trauma 16(1):39-44

22. Vochteloo AJ, Borger van der Burg BL, Mertens B, Niggebrugge AH, de Vries MR, Tuinebreijer WE et al (2011) Outcome in hip fracture patients related to anemia at admission and allogeneic blood transfusion: an analysis of 1262 surgically treated patients. BMC Musculoskelet Disord 12:262

23. Lu Q, Peng H, Zhou GJ, Yin D (2018) Perioperative blood management strategies for total knee arthroplasty. Orthop Surg 10(1):8-16

24. Phan DL, Rinehart JB, Schwarzkopf R (2015) Can tranexamic acid change preoperative anemia management during total joint arthroplasty? World J Orthop 6(7):521-527

25. Kapadia BH, Torre BB, Ullman N, Yang A, Harb MA, Grieco PW et al (2019) Reducing perioperative blood loss with antifibrinolytics and antifibrinolytic-like agents for patients undergoing total hip and total knee arthroplasty. J Orthop 16(6):513-516

26. Smith I, Kranke P, Murat I, Smith A, O'Sullivan G, Søreide E et al (2011) Perioperative fasting in adults and children: guidelines from the European Society of Anaesthesiology. Eur J Anaesthesiol 28(8):556-569

27. Awad S, Varadhan KK, Ljungqvist O, Lobo DN (2013) A meta-analysis of randomised controlled trials on preoperative oral carbohydrate treatment in elective surgery. Clin Nutr 32(1):34-44

28. Yuill KA, Richardson RA, Davidson HI, Garden OJ, Parks RW (2005) The administration of an oral carbohydrate-containing fluid prior to major elective upper-gastrointestinal surgery preserves skeletal muscle mass postoperatively — a randomised clinical trial. Clin Nutr 24(1):32-37

29. Tran S, Wolever TM, Errett LE, Ahn H, Mazer CD, Keith M (2013) Preoperative carbohydrate loading in patients undergoing coronary artery bypass or spinal surgery. Anesth Analg 117(2):305-313

30. Dilmen OK, Yentur E, Tunali Y, Balci H, Bahar M (2017) Does preoperative oral carbohydrate treatment reduce the postoperative surgical stress response in lumbar disc surgery? Clin Neurol Neurosurg 153:82-86

31. Lee SK, Lee JW, Choy WS (2013) Is multimodal analgesia as effective as postoperative patient-controlled analgesia following upper extremity surgery? Orthop Traumatol Surg Res 99(8):895-901

32. Pitchon DN, Dayan AC, Schwenk ES, Baratta JL, Viscusi ER (2018) Updates on multimodal analgesia for orthopedic surgery. Anesthesiol Clin 36(3):361-373

33. Fillingham YA, Hannon CP, Roberts KC, Mullen K, Casambre F, Riley C et al (2020) The efficacy and safety of nonsteroidal anti-inflammatory drugs in total joint arthroplasty: systematic review and direct metaanalysis. J Arthroplasty 35(10):2739-2758
34. Tan M, Law LS, Gan TJ (2015) Optimizing pain management to facilitate enhanced recovery after surgery pathways. Can J Anaesth 62(2):203-218

35. Mao Y, Wu L, Ding W (2016) The efficacy of preoperative administration of gabapentin/pregabalin in improving pain after total hip arthroplasty: a meta-analysis. BMC Musculoskelet Disord 17(1):373

36. YaDeau JT, Brummett CM, Mayman DJ, Lin Y, Goytizolo EA, Padgett DE et al (2016) Duloxetine and subacute pain after knee arthroplasty when added to a multimodal analgesic regimen: a randomized, placebocontrolled, triple-blinded trial. Anesthesiology 125(3):561-572

37. Koh IJ, Chang CB, Lee JH, Jeon YT, Kim TK (2013) Preemptive low-dose dexamethasone reduces postoperative emesis and pain after TKA: a randomized controlled study. Clin Orthop Relat Res 471(9):3010-3020

38. Lubis AMT, Rawung RBV, Tantri AR (2018) Preemptive analgesia in total knee arthroplasty: comparing the effects of single dose combining celecoxib with pregabalin and repetition dose combining celecoxib with pregabalin: double-blind controlled clinical trial. Pain Res Treat 2018:3807217

39. Apfel CC, Läärä E, Koivuranta M, Greim CA, Roewer N (1999) A simplified risk score for predicting postoperative nausea and vomiting: conclusions from cross-validations between two centers. Anesthesiology 91(3):693-700

40. Apfel CC, Korttila K, Abdalla M, Kerger H, Turan A, Vedder I et al (2004) A factorial trial of six interventions for the prevention of postoperative nausea and vomiting. N Engl J Med 350(24):2441-2451

41. Mauermann WJ, Shilling AM, Zuo Z (2006) A comparison of neuraxial block versus general anesthesia for elective total hip replacement: a meta-analysis. Anesth Analg 103(4):1018-1025

42. Alvarez A, Goudra BG, Singh PM (2017) Enhanced recovery after bariatric surgery. Curr Opin Anaesthesiol 30(1):133-139

43. Pu X, Sun JM (2019) General anesthesia vs spinal anesthesia for patients undergoing total-hip arthroplasty: a meta-analysis. Medicine (Baltimore) 98(16):e14925

44. Cole PJ, Craske DA, Wheatley RG (2000) Efficacy and respiratory effects of low-dose spinal morphine for postoperative analgesia following knee arthroplasty. Br J Anaesth 85(2):233-237

45. Fernandez MA, Karthikeyan S, Wyse M, Foguet P (2014) The incidence of postoperative urinary retention in patients undergoing elective hip and knee arthroplasty. Ann R Coll Surg Engl 96(6):462-465

46. Choi PT, Bhandari M, Scott J, Douketis J (2003) Epidural analgesia for pain relief following hip or knee replacement. Cochrane Database Syst Rev 3:CD003071

47. Wahood W, Yolcu Y, Alvi MA, Goyal A, Long TR, Bydon M (2019) Assessing the differences in outcomes between general and non-general anesthesia in spine surgery: results from a national registry. Clin Neurol Neurosurg 180:79-86

48. Brown CHT, Jones EL, Lin C, Esmaili M, Gorashi Y, Skelton RA et al (2019) Shaping anesthetic techniques to reduce post-operative delirium (SHARP) study: a protocol for a prospective pragmatic randomized controlled trial to evaluate spinal anesthesia with targeted sedation compared with general anesthesia in older adults undergoing lumbar spine fusion surgery. BMC Anesthesiol 19(1):192

49. Gille O, Obeid I, Degrise C, Guerin P, Skalli W, Vital JM (2007) The use of curare during anesthesia to prevent iatrogenic muscle damage caused by lumbar spinal surgery through a posterior approach. Spine 32(4):402-405

50. Kleimeyer JP, Harris AHS, Sanford J, Maloney WJ, Kadry B, Bishop JA (2018) Incidence and risk factors for postoperative hypothermia after orthopaedic surgery. J Am Acad Orthop Surg 26(24):e497-e503

51. Leijtens B, Koëter M, Kremers K, Koëter S (2013) High incidence of postoperative hypothermia in total knee and total hip arthroplasty: a prospective observational study. J Arthroplasty 28(6):895-898

52. Williams M, Ng M, Ashworth M (2018) What is the incidence of inadvertent hypothermia in elderly hip fracture patients and is this associated with increased readmissions and mortality? J Orthop 15(2):624-629

53. Temple-Oberle C, Shea-Budgell MA, Tan M, Semple JL, Schrag C, Barreto $M$ et al (2017) Consensus review of optimal perioperative care in breast reconstruction: Enhanced Recovery after Surgery (ERAS) Society recommendations. Plast Reconstr Surg 139(5):1056e-e1071

54. Rosenkilde C, Vamosi M, Lauridsen JT, Hasfeldt D (2017) Efficacy of prewarming with a self-warming blanket for the prevention of unintended 
perioperative hypothermia in patients undergoing hip or knee arthroplasty. J Perianesth Nurs 32(5):419-428

55. Bundgaard-Nielsen $M$, Secher NH, Kehlet H (2009) "Liberal" vs. "restrictive" perioperative fluid therapy - a critical assessment of the evidence. Acta Anaesthesiol Scand 53(7):843-51

56. Al-Ghamdi AA (2018) Intraoperative fluid management: past and future, where is the evidence? Saudi J Anaesth 12(2):311-317

57. Myles PS, Bellomo R, Corcoran T, Forbes A, Peyton P, Story D et al (2018) Restrictive versus liberal fluid therapy for major abdominal surgery. N Engl J Med 378(24):2263-2274

58. Miller TE, Pearse RM (2019) Perioperative fluid management: moving toward more answers than questions-a commentary on the RELIEF study. Perioper Med (Lond) 8:2

59. Giglio M, Dalfino L, Puntillo F, Brienza N (2019) Hemodynamic goaldirected therapy and postoperative kidney injury: an updated metaanalysis with trial sequential analysis. Crit Care 23(1):232

60. Madersbacher H, Cardozo L, Chapple C, Abrams P, Toozs-Hobson P, Young JS et al (2012) What are the causes and consequences of bladder overdistension? ICI-RS 2011. Neurourol Urodyn 31(3):317-321

61. Knight RM, Pellegrini VD Jr (1996) Bladder management after total joint arthroplasty. J Arthroplasty 11(8):882-888

62. Huang Z, Ma J, Shen B, Pei F (2015) General anesthesia: to catheterize or not? A prospective randomized controlled study of patients undergoing total knee arthroplasty. J Arthroplasty 30(3):502-506

63. Bjerregaard LS, Homilius M, Bagi P, Hansen TB, Kehlet H (2019) Indwelling urinary catheterisation may increase risk of complications in hip and knee arthroplasty. Dan Med J 66(4):A5538

64. Hansen E, Belden K, Silibovsky R, Vogt M, Arnold WV, Bicanic G et al (2014) Perioperative antibiotics. J Arthroplasty 29(2 Suppl):29-48

65. Tan TL, Shohat N, Rondon AJ, Foltz C, Goswami K, Ryan SP et al (2019) Perioperative antibiotic prophylaxis in total joint arthroplasty: a single dose is as effective as multiple doses. J Bone Joint Surg Am 101(5):429-437

66. Classen DC, Evans RS, Pestotnik SL, Horn SD, Menlove RL, Burke JP (1992) The timing of prophylactic administration of antibiotics and the risk of surgical-wound infection. N Engl J Med 326(5):281-286

67. Antimicrobial prophylaxis for surgery. Treat Guidel Med Lett 2009:7(82):47-52

68. Berríos-Torres SI, Umscheid CA, Bratzler DW, Leas B, Stone EC, Kelz RR et al (2017) Centers for disease control and prevention guideline for the prevention of surgical site infection, 2017. JAMA Surg 152(8):784-791

69. Calkins TE, Culvern C, Nam D, Gerlinger TL, Levine BR, Sporer SM et al (2020) Dilute betadine lavage reduces the risk of acute postoperative periprosthetic joint infection in aseptic revision total knee and hip arthroplasty: a randomized controlled trial. J Arthroplasty 35(2):538-43. e1

70. Jolivet S, Lucet JC (2019) Surgical field and skin preparation. Orthop Traumatol Surg Res 105(1s):S1-s6

71. Juelsgaard P, Larsen UT, Sørensen JV, Madsen F, Søballe K (2001) Hypotensive epidural anesthesia in total knee replacement without tourniquet: reduced blood loss and transfusion. Reg Anesth Pain Med 26(2):105-110

72. Gautam VK, Sambandam B, Singh S, Gupta P, Gupta R, Maini L (2013) The role of tranexamic acid in reducing blood loss in total knee replacement. J Clin Orthop Trauma 4(1):36-39

73. Haj-Younes B, Sivakumar BS, Wang M, An W, Lorentzos P, Adie S (2020) Tranexamic acid in hip fracture surgery: a systematic review and metaanalysis. J Orthop Surg (Hong Kong) 28(1):2309499019887995

74. Wong J, Abrishami A, El Beheiry H, Mahomed NN, Roderick Davey J, Gandhi R et al (2010) Topical application of tranexamic acid reduces postoperative blood loss in total knee arthroplasty: a randomized, controlled trial. J Bone Jt Surg Am 92(15):2503-2513

75. Roberts I, Shakur-Still H, Afolabi A, Akere A, Arribas M, Brenner A, Chaudhri R, Gilmore I, Halligan K, Hussain I, Jairath V (2020) Effects of a high-dose 24-h infusion of tranexamic acid on death and thromboembolic events in patients with acute gastrointestinal bleeding (HALT-IT): an international randomised, double-blind, placebo-controlled trial. Lancet 395(10241):1927-36

76. Kehlet $H$, Andersen L (2011) Local infiltration analgesia in joint replacement: the evidence and recommendations for clinical practice. Acta Anaesthesiol Scand 55(7):778-784
77. Li BL, Liu X, Cui L, Zhang W, Pang H, Wang M et al (2020) Local infiltration analgesia with ropivacaine improves postoperative pain control in ankle fracture patients: a retrospective cohort study. Pain Res Manag 2020:8542849

78. Sicard J, Klouche S, Conso C, Billot N, Auregan JC, Poulain S et al (2019) Local infiltration analgesia versus interscalene nerve block for postoperative pain control after shoulder arthroplasty: a prospective, randomized, comparative noninferiority study involving 99 patients. J Shoulder Elbow Surg 28(2):212-219

79. Andersen L, Kehlet $\mathrm{H}$ (2014) Analgesic efficacy of local infiltration analgesia in hip and knee arthroplasty: a systematic review. Br J Anaesth 113(3):360-374

80. Paul JE, Arya A, Hurlburt L, Cheng J, Thabane L, Tidy A et al (2010) Femoral nerve block improves analgesia outcomes after total knee arthroplasty: a meta-analysis of randomized controlled trials. Anesthesiology 113(5):1144-1162

81. Sharma S, lorio R, Specht LM, Davies-Lepie S, Healy WL (2010) Complications of femoral nerve block for total knee arthroplasty. Clin Orthop Relat Res 468(1):135-140

82. Aggarwal VK, Elbuluk A, Dundon J, Herrero C, Hernandez C, Vigdorchik JM et al (2019) Surgical approach significantly affects the complication rates associated with total hip arthroplasty. Bone Joint J. 101 (6):646-51

83. Zhang W, Li N, Chen S, Tan Y, Al-Aidaros M, Chen L (2014) The effects of a tourniquet used in total knee arthroplasty: a meta-analysis. J Orthop Surg Res 9(1):13

84. Kelly EG, Cashman JP, Imran FH, Conroy R, O'Byrne J (2014) Systematic review and meta-analysis of closed suction drainage versus non-drainage in primary hip arthroplasty. Surg Technol Int 24:295-301

85. Payne DH, Fischgrund JS, Herkowitz HN, Barry RL, Kurz LT, Montgomery DM (1996) Efficacy of closed wound suction drainage after single-level lumbar laminectomy. J Spinal Disord 9(5):401-403

86. Brown MD, Brookfield KF (2004) A randomized study of closed wound suction drainage for extensive lumbar spine surgery. Spine 29(10):1066-8

87. Mirzai H, Eminoglu M, Orguc S (2006) Are drains useful for lumbar disc surgery? A prospective, randomized clinical study. J Spinal Disord Tech 19(3):171-177

88. Kanayama M, Oha F, Togawa D, Shigenobu K, Hashimoto T (2010) Is closed-suction drainage necessary for single-level lumbar decompression? Review of 560 cases. Clin Orthop Relat Res 468(10):2690-2694

89. Zhong Y, Zheng C, Du W, Zheng J, Xu S, Tong P (2021) Mirabilite with ice pack after total knee arthroplasty: a randomized controlled trial study. Evid Based Complement Alternat Med 2021:6611614

90. Geerts WH, Bergqvist D, Pineo GF, Heit JA, Samama CM, Lassen MR et al (2008) Prevention of venous thromboembolism: American College of Chest Physicians Evidence-Based Clinical Practice Guidelines (8th edition). Chest 133(6 Suppl):381s-453s

91. Flevas DA, Megaloikonomos PD, Dimopoulos L, Mitsiokapa E, Koulouvaris P, Mavrogenis AF (2018) Thromboembolism prophylaxis in orthopaedics: an update. EFORT Open Rev 3(4):136-148

92. Flierl MA, Messina MJ, Mitchell JJ, Hogan C, D'Ambrosia R (2015) Venous thromboembolism prophylaxis after total joint arthroplasty. Orthopedics 38(4):252-263

93. Park Y-S (2011) Guideline for the prophylaxis of venous thromboembolism in hip surgery patients. J Korean Orthop Assoc 46(2):95-98

94. Husted H, Otte KS, Kristensen BB, Ørsnes T, Wong C, Kehlet H (2010) Low risk of thromboembolic complications after fast-track hip and knee arthroplasty. Acta Orthop 81(5):599-605

95. Harper CM, Lyles YM (1988) Physiology and complications of bed rest. J Am Geriatr Soc 36(11):1047-1054

96. Guerra ML, Singh PJ, Taylor NF (2015) Early mobilization of patients who have had a hip or knee joint replacement reduces length of stay in hospital: a systematic review. Clin Rehabil 29(9):844-854

97. Deng Z, Wu J, Tang K, Shu H, Wang T, Li F et al (2021) In adults, early mobilization may be beneficial for distal radius fractures treated with open reduction and internal fixation: a systematic review and metaanalysis. J Orthop Surg Res 16(1):691

98. Scott NB, McDonald D, Campbell J, Smith RD, Carey AK, Johnston IG et al (2013) The use of enhanced recovery after surgery (ERAS) principles in Scottish orthopaedic units-an implementation and follow-up 
at 1 year, 2010-2011: a report from the Musculoskeletal Audit. Scotland Arch Orthop Trauma Surg 133(1):117-124

99. Gwynne-Jones DP, Martin G, Crane C (2017) Enhanced recovery after surgery for hip and knee replacements. Orthop Nurs 36(3):203-210

100. Auyong DB, Allen CJ, Pahang JA, Clabeaux JJ, MacDonald KM, Hanson NA (2015) Reduced length of hospitalization in primary total knee arthroplasty patients using an updated Enhanced Recovery After Orthopedic Surgery (ERAS) pathway. J Arthroplasty 30(10):1705-1709

101. Deng QF, Gu HY, Peng WY, Zhang Q, Huang ZD, Zhang C et al (2018) Impact of enhanced recovery after surgery on postoperative recovery after joint arthroplasty: results from a systematic review and metaanalysis. Postgrad Med J 94(1118):678-693

102. Garriga C, Murphy J, Leal J, Price A, Prieto-Alhambra D, Carr A et al (2019) Impact of a national enhanced recovery after surgery programme on patient outcomes of primary total knee replacement: an interrupted time series analysis from "The National Joint Registry of England, Wales, Northern Ireland and the Isle of Man." Osteoarthr Cartil 27(9):1280-1293

103. Jiang HH, Jian XF, Shangguan YF, Qing J, Chen LB (2019) Effects of enhanced recovery after surgery in total knee arthroplasty for patients older than 65 years. Orthop Surg 11(2):229-235

104. Yin M, Yan Y, Fan Z, Fang N, Wan H, Mo W et al (2020) The efficacy of Enhanced Recovery after Surgery (ERAS) for elderly patients with intertrochanteric fractures who received surgery: study protocol for a randomized, blinded, controlled trial. J Orthop Surg Res 15(1):91

105. Wang P, Wang Q, Kong C, Teng Z, Li Z, Zhang S et al (2020) Enhanced recovery after surgery (ERAS) program for elderly patients with shortlevel lumbar fusion. J Orthop Surg Res 15(1):299

106. Ripollés-Melchor J, Abad-Motos A, Díez-Remesal Y, Aseguinolaza-Pagola M, Padin-Barreiro L, Sánchez-Martín R et al (2020) Association between use of Enhanced Recovery After Surgery protocol and postoperative complications in total hip and knee arthroplasty in the postoperative outcomes within enhanced recovery after surgery protocol in elective total hip and knee arthroplasty study (POWER2). JAMA Surg 155(4):e196024

107. Frassanito L, Vergari A, Nestorini R, Cerulli G, Placella G, Pace V et al (2020) Enhanced recovery after surgery (ERAS) in hip and knee replacement surgery: description of a multidisciplinary program to improve management of the patients undergoing major orthopedic surgery. Musculoskelet Surg 104(1):87-92

108. Liu SY, Li C, Zhang PX (2021) Enhanced recovery after surgery for hip fractures: a systematic review and meta-analysis. Perioper Med (Lond) 10(1):31

109. Kang Y, Liu J, Chen H, Ding W, Chen J, Zhao B et al (2019) Enhanced recovery after surgery (ERAS) in elective intertrochanteric fracture patients result in reduced length of hospital stay (LOS) without compromising functional outcome. J Orthop Surg Res 14(1):209

110. Tong Y, Fernandez L, Bendo JA, Spivak JM (2020) Enhanced recovery after surgery trends in adult spine surgery: a systematic review. Int J Spine Surg 14(4):623-640

111. Sun K (2020) Clinical application of enhanced recovery after surgery in the perioperative period of anterior cruciate ligament reconstruction. Chin J Tissue Eng Res 25:1647-51

112. Hu ZC, He LJ, Chen D, Li XB, Feng ZH, Fu CW et al (2019) An enhanced recovery after surgery program in orthopedic surgery: a systematic review and meta-analysis. J Orthop Surg Res 14(1):77

113. Xiao H, LiT, Mi M, Zhou L, Liu H, Gao Z et al (2019) Enhanced Recovery After Surgery used in close reduction of distal radius fracture in emergency traumatic patients: a prospective cohort study. Chin J Orthop Trauma 12:945-51

114. Leiss F, Götz JS, Maderbacher G, Meyer M, Reinhard J, Zeman F et al (2021) Excellent functional outcome and quality of life after primary cementless total hip arthroplasty (THA) using an enhanced recovery setup. J Clin Med 10(4):621

115. Pritchard MG, Murphy J, Cheng L, Janarthanan R, Judge A, Leal J (2020) Enhanced recovery following hip and knee arthroplasty: a systematic review of cost-effectiveness evidence. BMJ Open 10(1):e032204

116. Roth EM, Wong DJ, Poylin VY, Messaris E, Cataldo TE (2021) Delivery of ERAS care in an academic hospital: an analysis of pathway deviations and obstacles to adherence. Am J Med Qual 36(5):320-7
117. Pooya S, Johnston K, Estakhri P, Fathi A (2021) Successful implementation of enhanced recovery after surgery program in a safety-net hospital: barriers and facilitators. J Perianesth Nurs 36(5):468-72

118. Lam JY, Howlett A, McLuckie D, Stephen LM, Else SDN, Jones A et al (2021) Developing implementation strategies to adopt Enhanced Recovery After Surgery (ERAS ${ }^{\circledR}$ ) guidelines. BJS Open. 5(2):zraa011

119. Drew S, Judge A, Cohen R, Fitzpatrick R, Barker K, Gooberman-Hill R (2019) Enhanced recovery after surgery implementation in practice: an ethnographic study of services for hip and knee replacement. BMJ Open 9(3):e024431

120. Roulin D, Muradbegovic M, Addor V, Blanc C, Demartines N, Hübner M (2017) Enhanced recovery after elective colorectal surgery —reasons for non-compliance with the protocol. Dig Surg 34(3):220-226

121. Foni NO, Costa LAV, Paião ID, Oliveira IO, Carvalho RT, Lenza M et al (2020) Clinical pathway improves medical practice in total knee arthroplasty. PLoS ONE 15(5):e0232881

122. Schwarzkopf R, Zamansani T, Houng M, Bridgeman T (2016) The effect of a clinical pathway strategy for managing care in total joint replacement: the impact on perioperative outcomes. J Clin Exp Orthop 2:11

123. Ament SM, Gillissen F, Moser A, Maessen JM, Dirksen CD, von Meyenfeldt MF et al (2014) Identification of promising strategies to sustain improvements in hospital practice: a qualitative case study. BMC Health Serv Res 14:641

\section{Publisher's Note}

Springer Nature remains neutral with regard to jurisdictional claims in published maps and institutional affiliations.

Ready to submit your research? Choose BMC and benefit from:

- fast, convenient online submission

- thorough peer review by experienced researchers in your field

- rapid publication on acceptance

- support for research data, including large and complex data types

- gold Open Access which fosters wider collaboration and increased citations

- maximum visibility for your research: over $100 \mathrm{M}$ website views per year

At BMC, research is always in progress.

Learn more biomedcentral.com/submissions 